Cite as: Ivtzan, I., Young, T., Martman, J., Jeffrey, A., Lomas, T., Hart, R., \& Eiroa-Orosa, F. J. (2016). Integrating Mindfulness into Positive Psychology: a Randomised Controlled Trial of an Online Positive Mindfulness Program. Mindfulness, 7(6), 1396-1407. https://doi.org/10.1007/s12671-016-0581-1

\title{
Integrating Mindfulness into Positive Psychology: A Randomised Controlled Trial of an Online Positive Mindfulness Program
}

\begin{abstract}
The purpose of the present study was to test the efficacy of an 8-week online intervention-based Positive Mindfulness Program (PMP) that integrated mindfulness with a series of positive psychology variables, with a view to improving wellbeing scores measured in these variables. The positive mindfulness cycle, based on positive intentions and savouring, provides the theoretical foundation for the PMP. The study was based on a randomised wait-list controlled trial; and 168 participants $(128$ females, mean age $=40.82)$ completed the intervention which included daily videos, meditations, and activities. The variables tested included wellbeing measures, such as gratitude, self- compassion, selfefficacy, meaning, and autonomy. Pre- and post- intervention data, including one month after the end of the intervention, were collected from both experimental and control groups. The post-test measurements of the experimental participants showed a significant improvement in all the dependent variables compared with the pre-test ones and were also significantly higher than those of the control group. One month after the intervention, the experimental group participants retained their improvement in 10 out of the 11 measurements. These positive results indicate that PMP may be effective in enhancing wellbeing and other positive variables in adult, non-clinical populations.
\end{abstract}

Keywords: wellbeing; mindfulness; meditation; positive psychology; randomised controlled trial; intervention program. 


\section{Introduction}

A large body of research has demonstrated that mindfulness training has positive effects (e.g., Baer, Lykins, \& Peters, 2012; Ivtzan \& Lomas, 2016), but the number of mindfulness programs explicitly aimed at positive psychological changes and increased wellbeing is small (Lindsay \& Creswell, 2015). In addition, empirical reports have mainly focused on mindfulness interventions as programs that reduce psychological distress (Goyal et al., 2014). These programs reflect an existing gap in the current mindfulness literature: the focus on negative variables (such as stress and anxiety), while neglecting the potential role of mindfulness in the enhancement of positive ones (such as happiness and meaning). The practice of mindfulness has been correlated with reduced attentional biases in response to negative stimuli (Goldin \& Gross, 2010). And yet, letting go of the fixation on negative cognitive and emotional responses is not sufficient to promote positive variables and wellbeing: “... a complete theory of mindfulness must account for the cultivation of positive mental states rather than focus exclusively on the reduction of negative states" (Garland, Farb, Goldin, \& Fredrikson, 2015, p. 295).

An area where these questions could be resolved is positive psychology (PP). Wellbeing has been studied extensively within the field of PP (Lomas, Hefferon, \& Ivtzan, 2014). More specifically, positive psychology interventions (PPIs) have been successfully used to strengthen positive mental states and a variety of wellbeing variables (Parks \& Biswas-Diener, 2013). Kashdan et al (2015) indicated that mindfulness responses to stressors and negative events are much more studied than the effect of mindfulness during positive event processing. Similarly, Lindsay and Creswell (2015) claimed that new studies are needed where mindfulness interventions attempt to increase positive wellbeing variables as part of the training. These are gaps that PP could and should address. 
Mindfulness is a form of awareness that arises from attending to the present moment in a non-judgemental, and accepting manner (Bishop et al., 2004). This state of mind is an invitation for the practitioner to attend the full range of internal and external experiences with a non-judgemental stance (Hart, Ivtzan, \& Hart, 2013). Studies have shown that mindfulness promotes both hedonic (Brown \& Cordon, 2009) and eudaimonic wellbeing (Brown, Ryan, \& Creswell, 2007). Hedonic wellbeing is associated with pain relief and increased pleasure; eudaimonic wellbeing stands for living a meaningful, selfrealised, and fully-functional life.

Various mindfulness programs have been developed in the West for clinical populations, the most prominent of which include mindfulness-based stress reduction (MBSR; Kabat-Zinn, 1982) and mindfulness-based cognitive therapy (MBCT; Teasdale et al., 2000). As implied by its name, the purpose of MBSR, originally designed to manage chronic pain, was to decrease stress, anxiety, and depression, while the MBCT aimed specifically to prevent depression relapses. These programs have been empirically tested, and successfully used to reduce a variety of symptoms related to disorders such as: psychosis (Bach \& Hayes, 2002), depression (Teasdale et al., 2000) and chronic pain (Kabat-Zinn, 1982). They focus on reducing negative variables (such as stress, anxiety, and depression), in line with the traditional Western psychology focus on reducing deficits (Seligman \& Csikszentmihalyi, 2000).

Despite the focus on deficit reduction, Western mindfulness programs have also led to improvements in positive variables, such as positive affect (Geschwind, Peeters, Drukker, van Os \& Wichers, 2011), cognitive functioning (Hölzel et al., 2011), positive reappraisal of thoughts (Hanley \& Garland, 2014), and improved interpersonal interactions (Goleman, 2006). This may wrongly suggest that, because existing deficit- focused mindfulness programs increase positive variables, there is no need for a separate 
mindfulness program focused on positive variables. Such an approach would be missing the potential benefits embodied in the combination of PP and mindfulness.

The relationship between mindfulness and PP has been explored in the past (e.g., Ivtzan \& Lomas, 2016; Brown \& Ryan, 2003), and yet this paper provides a unique theoretical foundation for the relationship between PPIs and mindfulness. We propose the positive mindfulness cycle whereby PPIs and mindfulness influence and enhance each other in a process leading to improvements in Hedonic and Eudaimonic wellbeing. This cyclic process allows mindfulness and PPIs to continuously enhance each other, thus leading to an increase in an individual's wellbeing which could serve better than the beneficial impact of mindfulness or PPIs as separate practices.

Shapiro et al. (2006) proposed the IAA model of mindfulness, as part of which the first element of the model, intention, creates a specific context and motivation, fuelling mindfulness practice, in that it connects practitioners with their goals, vision, and aspirations. Shapiro et al. (2006) viewed these experiences as a vital component of mindfulness, and maintained that the practitioner's intention in practising mindfulness plays an important role in the very experience of mindfulness exercises, and consequently in their outcomes. Kabat-Zinn (1990) argued that intention is essential in facilitating positive change through mindfulness: "Your intentions set the stage for what is possible. They remind you from moment to moment of why you are practicing in the first place" (p. 32). Shapiro (1992a) underscored the importance of intention, showing that the majority of meditators have attained the effects they had originally aimed for. For example, if they aimed for self-regulation (control over self) they were more likely to achieve greater selfregulation while the intention of self-exploration (knowledge of self) led to increased selfexploration. 
Parks and Biswas-Diener (2013) outlined a number of rigorous parameters for the classification of PPIs, beginning with a flourishing-based approach according to which PPIs have a clear goal and intention, to increase positive variables. In reality, the primary intention of all the prominent mindfulness programs, including the MBSR and the MBCT, was decreasing negative variables; this is a deficit-based approach, whose point of departure and implied motivation and intention is the disease model: human beings are seen as being damaged, in need of treatment, and we harness mindfulness to that purpose. These programs are therefore not in line with the spirit of PPIs, whose intentions regard mental health from a different angle. In PPIs, mental health does not mean the absence of mental illnesses; these programs do not consider eliminating illness as a guarantee that an individual is healthy, thriving, and competent (Ryff \& Singer, 1998). Keyes (2002) defined flourishing as the presence of mental health which is a combination of positive functioning and feelings. This state of flourishing goes beyond the mere elimination of psychological distress, and can be achieved only if positive variables are involved. The deficit focus of Western psychology has generated much research on the ability of mindfulness to reduce negative variables, but very little research has been dedicated to mindfulness-based interventions and mechanisms which boost positive variables.

Garland et al. (2015) proposed the Mindfulness-To-Meaning theory in order to clarify potential paths through which mindfulness practice enhances positive variables, mainly Eudaimonic wellbeing. As part of their theory, they suggested that mindfulness practice helps enhance savouring. Savouring allows us to voluntarily generate, intensify, and prolong enjoyment and appreciation (Bryant \& Veroff, 2007).

According to Ritchie and Bryant (2012), mindfulness is a prominent dimension of savouring. It is through the quality of befriending and embracing whatever arises that mindfulness allows one to savour. Savouring is enhanced by mindfulness practice, in that 
it involves metacognitive and self-reflective elements, enabling the individual to be aware of the pleasurable aspects of the stimulus as well as the positive emotions that are triggered while engaged in it (Frijda \& Sundararajan, 2007). Mindfulness enables us to monitor on-going sensory and perceptual events, thereby facilitating the noticing and appreciation that allows savouring (Lindsay \& Creswell, 2015).

In our everyday lives, pleasant events outnumber unpleasant ones by a ratio of 3 to 1 (Oishi, Diener, Choi, Kim-Prieto, \& Choi, 2007); therefore, most moments in life have the potential to be experienced as positive. However, we essentially need to be aware of these pleasant moments in order to enjoy them. Without being mindfully aware of a positive experience, an individual will not be able to savour it. A broad range of studies supported this notion, and indicated that increased attention to sensory experience promotes pleasure in activities, such as sex and eating (Heiman \& Meston, 1997), while focusing our full attention on the actual experience of the moment leads to higher levels of happiness (Killingsworth \& Gilbert, 2010). Specifically linking mindfulness with savouring, mindfulness training increased participants' positive emotions and rewards following pleasant daily life activities (Geschwind et al., 2011). Mindful eating studies showed similar results when participants increased liking and enjoyment of food following mindfulness practice (Hong, Lishner \& Han, 2014). Finally, Loving-Kindness- Meditation (LKM) studies have displayed similar results (Fredrickson et al., 2008).

In the context of PPIs, it is important to remember that experiencing positive events or emotions does not automatically mean that an individual can fully savour them. The management of positive experiences and emotions requires - beyond the feeling of pleasure, meaning, or any other positive variable - the capacity to find, regulate, manipulate, and sustain them. 
Therefore, in order to fully utilise the benefits of PPIs, savouring is required. This understanding underlines the fact that mindfulness, which boosts savouring, enhances the benefits of PPI practice.

To find out whether participation in an online Positive Mindfulness Program (PMP) actually increased wellbeing, eleven variables were measured for changes: nine wellbeing variables (mindfulness, gratitude, self-compassion, autonomy, self-efficacy, presence of meaning, wellbeing - happiness index, compassion for others, and engagement), and two psychological distress variables (depression and perceived stress). While focusing on positive variables, the present study examined whether the PMP is also able to reduce depression and perceived stress, two major deficiency-based negative variables. We hypothesised that participants who received the PMP training would show significant improvements in both wellbeing variables and psychological distress variables. A secondary hypothesis was that participants with lower levels of wellbeing and higher levels of depression will benefit to a greater extent from the program.

\section{Method}

\section{Participants}

The study used a randomised wait-list controlled design. Our main between-group independent variable was the allocation to a control or an experimental group. A convenience sample, composed by three different population groups were targeted in the recruitment process: Educators, office workers and meditators. 'Educators' included people who were educating others in a group setting, e.g. school teachers. 'Office workers' were people working for at least seven hours a week in an office setting. 'Meditators' were people who had meditated at least once a week for at least one year. Meditation, in this context, was defined as any activity where a conscious attempt is made to focus attention in a non-analytical way; examples included breathing and walking 
meditation, body-scan, and yoga. The inclusion of this subsample intended to allow analysing whether previous practice of meditation had buffering effects on the results.

The sample size was calculated accepting an alpha risk of 0.05 and a beta risk of 0.2 in a two-sided test with a minimum correlation coefficient between the initial and final measurement of 0.5 . Foreseeing a dropout rate twice as high in the control compared with the treatment group, in order to recognize as statistically significant a difference greater than or equal to 0.5 standard deviations (effect chosen as a way to make the study feasible), 48 participants were necessary in the experimental group and 95 participants were necessary in the control group. The experimental procedure was carried out until these numbers were achieved.

Participants were recruited online through social networks and forums. The program was advertised as voluntary, and was described as a combination of mindfulness and positive psychology exercises. No incentives were offered. 455 participants were initially recruited, of whom 15 were excluded for severe levels of depression (as measured with the BDI cut off established by Beck, Steer, Ball \& Ranieri, 1996) following initial completion of questionnaires. This screening was deemed necessary based on studies indicating that meditation can have adverse effects on severely depressed individuals (Shapiro, 1992b). Another criterion excluded participants under the age of 18, but none appeared on the initial recruit list.

Of the remaining 440 participants, 394 completed at least one questionnaire. The number of participants who completed all the questionnaires finally reached $168 ; 115$ were in the control group and 53 in the experimental group. The participants included citizens of 20 countries, with most of them from the United Kingdom (32\%), Canada (24\%), the United States (13.5\%) and Australia (11\%). All participants were English-speaking. 


\section{Procedure}

The Positive Mindfulness Program (PMP) introduced in this paper is an 8-week online program, which combines mindfulness training with various PPIs and theoretical aspects to boost wellbeing in the general population. This is the result of a long trajectory of research that was piloted with university students before being implemented in this study. Each of the eight PMP weeks focused on a different topic: 1) self-awareness 2) positive emotions 3) self-compassion 4) self-efficacy (strengths) 5) autonomy 6) meaning 7) positive relations with others and 8) engagement (savouring). These topics address both hedonic and eudaimonic wellbeing. For example, mindfulness increased both hedonic and eudaimonic wellbeing (Brown, Ryan, \& Creswell, 2007). Engagement and gratitude increased positive emotions (McCullough, Emmons, \& Tsang, 2002) that promote hedonic wellbeing (Deci \& Ryan, 2008). The other positive variables promoted eudaimonic wellbeing based on the psychological wellbeing (PWB) model (Ryff \& Keyes, 1995). The model outlined six dimensions of wellbeing, five of which are included in the PMP: selfacceptance (self-compassion), autonomy, environmental mastery (self- efficacy), purpose in life (meaning), and positive relations with others.

At the beginning of each week, the experimental participants were given an 8-10 minute video, which summarised the theoretical basis of the weekly topic. They were also given a 12 minute audio file which contained a daily guided-meditation running for about 10 minutes, and an additional 2-minute brief daily activity related to the week's topic (see Table 1). These daily meditations are at the core of the PMP and yet the program requires a third stage: daily practice. This daily practice was an invitation for the participants to apply the insights, internal experiences and knowledge triggered by the daily meditations to their everyday lives. Many spiritual teachers emphasise the importance meditation acquires once it becomes an integrated aspect of life rather than an island within our daily 
activities (e.g., Krishnamurti, 1975). The daily practice included in the PMP was an important bridge connecting the daily meditations with the participants' daily life, allowing them to apply their meditative insights.

A written transcript of the meditations and daily activities was also provided. The PMP is fully protocoled, including all the materials used for the videos, daily meditations, and daily activities. The videos and meditations were created by a team of researchers, who are the authors. With 20 years of mindfulness mediation practice and over 15 years' experience teaching a broad range of meditation techniques (including mindfulness meditation), the leading author recorded the sessions. The weekly topics and activities are summarised in Table 1. 
Table 1: Outline of PMP eight weekly topics and activities

\begin{tabular}{|c|c|c|c|c|}
\hline Week & Variable & Theory Video & Meditation & Daily Practice \\
\hline 1 & $\begin{array}{l}\text { Self- } \\
\text { Awareness }\end{array}$ & $\begin{array}{l}\text { Introduction to } \\
\text { mindfulness, self- } \\
\text { awareness, positive } \\
\text { psychology and meditation }\end{array}$ & $\begin{array}{l}\text { Introductory } \\
\text { meditation focusing } \\
\text { on awareness of } \\
\text { breath, body and } \\
\text { emotions }\end{array}$ & $\begin{array}{l}\text { Keeping aware of } \\
\text { thoughts and reactions } \\
\text { throughout the day }\end{array}$ \\
\hline 2 & $\begin{array}{l}\text { Positive } \\
\text { emotions }\end{array}$ & $\begin{array}{l}\text { Discussion of the benefits } \\
\text { of positive emotions and } \\
\text { gratitude }\end{array}$ & $\begin{array}{l}\text { Gratitude meditation } \\
\text { focusing on who or } \\
\text { what one appreciates }\end{array}$ & $\begin{array}{l}\text { Expressing gratitude for } \\
\text { positive situations }\end{array}$ \\
\hline 3 & $\begin{array}{l}\text { Self- } \\
\text { compassion }\end{array}$ & $\begin{array}{l}\text { Explanation of the self- } \\
\text { compassion concept, } \\
\text { research review, and } \\
\text { methods to increase self- } \\
\text { compassion }\end{array}$ & $\begin{array}{l}\text { Adapted version of } \\
\text { Loving Kindness } \\
\text { meditation focusing } \\
\text { on self-compassion } \\
\text { (Neff \& Germer, } \\
\text { 2013) }\end{array}$ & $\begin{array}{l}\text { Replacing internal } \\
\text { criticism with statements } \\
\text { of kindness }\end{array}$ \\
\hline 4 & Self-efficacy & $\begin{array}{l}\text { Introduction to character } \\
\text { strengths and self-efficacy } \\
\text { including enhancement } \\
\text { methods }\end{array}$ & $\begin{array}{l}\text { Meditation focusing } \\
\text { on a time when } \\
\text { participant was at } \\
\text { his/her best and using } \\
\text { character strengths }\end{array}$ & $\begin{array}{l}\text { Completing the VIA } \\
\text { (Values in Action) } \\
\text { character strengths } \\
\text { questionnaire (Peterson, } \\
\& \text { Seligman, 2006) and } \\
\text { using strengths }\end{array}$ \\
\hline 5 & Autonomy & $\begin{array}{l}\text { Introduction to autonomy } \\
\text { and its connection with } \\
\text { wellbeing }\end{array}$ & $\begin{array}{l}\text { Meditation on } \\
\text { authentic self and } \\
\text { action }\end{array}$ & $\begin{array}{l}\text { Taking action in line with } \\
\text { one's values and noticing } \\
\text { external pressure on } \\
\text { choices }\end{array}$ \\
\hline 6 & Meaning & $\begin{array}{l}\text { Discussion of meaning and } \\
\text { wellbeing. Completion of } \\
\text { writing exercise, "Best } \\
\text { Possible Legacy" adapted } \\
\text { from the Obituary Exercise } \\
\text { (Seligman, Rashid \& } \\
\text { Parks, } \\
\text { nnกム) }\end{array}$ & $\begin{array}{l}\text { Meditation on future } \\
\text { vision of self, } \\
\text { living one's best } \\
\text { possible legacy }\end{array}$ & $\begin{array}{l}\text { Acting according to best } \\
\text { possible legacy. } \\
\text { Choosing } \\
\text { meaningful activities }\end{array}$ \\
\hline 7 & $\begin{array}{l}\text { Positive } \\
\text { relations with } \\
\text { others }\end{array}$ & $\begin{array}{l}\text { Discussion of benefits of } \\
\text { positive relationships and } \\
\text { methods for relationship } \\
\text { enhancement }\end{array}$ & $\begin{array}{l}\text { Loving Kindness } \\
\text { Meditation (Scheffel, } \\
\text { 2003) }\end{array}$ & $\begin{array}{l}\text { Bringing feelings of } \\
\text { loving-kindness } \\
\text { into } \\
\text { interactions }\end{array}$ \\
\hline 8 & Engagement & $\begin{array}{l}\text { Introduction to } \\
\text { engagement and savouring } \\
\text { and their connection with } \\
\text { positive emotions }\end{array}$ & $\begin{array}{l}\text { Savouring meditation } \\
\text { focusing on food }\end{array}$ & $\begin{array}{l}\text { Using savouring to } \\
\text { engage with experiences }\end{array}$ \\
\hline & Conclusion & $\begin{array}{l}\text { Summary of the program. } \\
\text { Discussion of personal } \\
\text { growth and invitation to } \\
\text { keep meditating. }\end{array}$ & & \\
\hline
\end{tabular}


How are PP and mindfulness amalgamated in the PMP? The daily PMP sessions involved two dimensions. The first is based on PP exercises or interventions, where participants engaged with their own strengths and virtues. In this stage, approximately half of the set practice time was dedicated to the exercise, creating a positive inner experience that is both cognitive and emotional. This first dimension may elicit, for example, positive emotions, a sense of autonomy, intensified personal meaning in life, greater connection with one's strengths, or a deep feeling of self-compassion. Once the engagement with the PPI has been completed, the practice shifted to the second dimension: mindfulness. As is commonly the case in mindfulness practice, participants simply observed their inner experience without reacting to it. These dimensions have been repeated throughout the intervention, where participants moved from a PPI into mindfulness, back to a PPI leading to mindfulness, creating the positive mindfulness cycle. As part of the cycle, a flourishing-based intention was created through the PPI, enhancing mindfulness, while a deeper level of savouring towards the PPI was provided through mindfulness.

This process could have enhanced participants' wellbeing, as part of the PMP, as it utilised further the benefits of both practices. For example, in the sixth week, participants performed a daily exercise designed to boost meaning in life and create greater awareness of this meaning. They began with practising the "best possible self" intervention (King, 2001) for approximately five minutes, to trigger insights related to aspects of the self which could lead to higher levels of meaning and purpose. This has been the process of intention setting. Once it has been completed, participants continued with five minutes of mindfulness practice, during which they engaged non-reactively and non-judgementally with thoughts and sensations in the body that have been triggered by their own experience of their "best possible self". This is the process that increased the 
level of savouring towards the experience of their "best possible self". The daily practice allowed gradual growth of the positive cycle, enhancing its benefits.

Following recruitment, participants received an invitation letter by email, outlining the program which contained a link to a designated online platform. Participants were asked to complete the consent form, and were screened for depression. After filling in that information, participants were randomly distributed into experimental and control groups, and were then sent an email containing instructions for further participation. Randomisation was executed by means of predefined lists (440 numbers, range 1-2, balanced) created automatically by the study's website. Participants who passed the screening completed a one-page demographic questionnaire and the 11-scale questionnaire that provided the pretest data. Participants were also requested to indicate their experience with meditation (number of years). Mean completion time was 25 minutes.

After the pre-test stage, the experimental and control groups followed a different procedure. The experimental group began the PMP immediately: The participants were invited to watch the videos, and then proceed with the meditation and the other indicated practice every day for the next week. A practice-reminder email was sent to the participants after three days, and another one was sent after seven days, inviting them to login and carry on with the program. Once logged-in, they were asked to report how frequently they had completed the meditation and daily activity during the week. To assist this process they were provided with a tracking table. The participants then completed the relevant scales for the week and went on to the video and audio file of the next week. This process continued for eight weeks. At the end of the program the participants completed again the same 11 scales to provide post-test measures. This was repeated one month later to provide a longitudinal perspective. Participants needed to view the videos of all sessions, and listen to all audio meditations at least once, in order to receive the post- 
treatment assessments. Meanwhile, the control group was informed they were on a 'waitlist' and could start the program in three months. Eight weeks later they were asked to complete the 11 scales. This was repeated after another four weeks (12 weeks in all), providing two measures, a month apart, which parallel with the post-tests of the experimental group. They were then given access to the PMP.

The research was approved by the Institutional Ethics Review Board of the University of East London. Following completion, both control and experimental participants were provided with a debrief letter, explaining the aims of the program. Figure 1 shows a flow chart of the procedure and participant numbers. 
Figure 1. Participant Flow Diagram

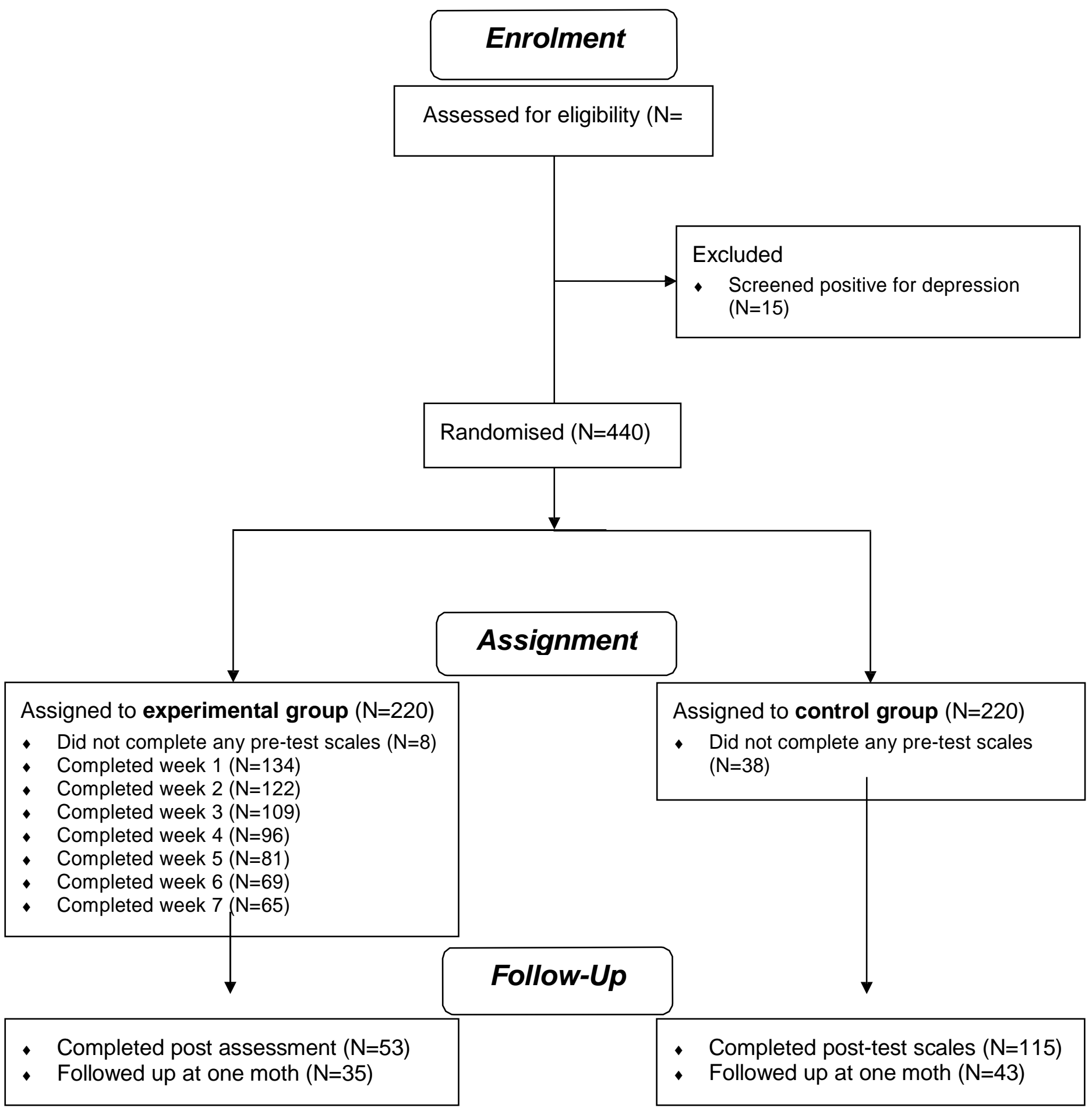




\section{Measures}

Outcome variables were measured by quantitative self-reported scales that were completed online. Eleven scales were used as pre- and post-measures. The post-measures were taken at the completion of the program and one month later. The experimental group also completed the Pemberton Happiness Index - Experienced Wellbeing Subscale (Hervás \& Vázquez, 2013) and the average of minutes meditating per day on every week of the program.

\section{Wellbeing - The Pemberton happiness index (PHI).}

The PHI (Hervás \& Vázquez, 2013) is a 21-item scale that measures eudaimonic and hedonic wellbeing. It has two subscales: Remembered wellbeing (PHI-RW) and Experienced wellbeing (PHI-EW). The PHI-RW is made of retrospective questions, scored on a 10-point Likert scale. The PHI-EW comprises ten 'yes' or 'no' questions that measure wellbeing in the preceding 24 hours, with good internal reliability $(\alpha=0.897)$ at baseline.

\section{Perceived stress scale - 10 item form (PSS)}

The PSS (Cohen \& Williamson, 1988) measures perceived stressful situations. It is made of 10 items scored on a 5-point Likert scale, with good internal reliability $(\alpha=0.906)$.

\section{Beck's depression inventory-II (BDI-II)}

The BDI-II (Beck et al., 1996) measures depression over 21 items. It is scored on a 4point Likert scale, with good internal reliability $(\alpha=0.816)$.

\section{Freiburg mindfulness inventory, short form (FMI)}

Mindfulness was assessed using the FMI (Walach, Buchheld, Buttenmüller, Kleinknecht, $\&$ Schmidt, 2006). The FMI is a 14-item scale, scored on a 4-point Likert scale, with good internal reliability $(\alpha=0.907)$. 


\section{Gratitude Questionnaire Six Item Form (GQ6)}

The GQ6 comprises six items which measure the respondents' disposition to feel gratitude (McCullough et al., 2002). It is scored on a 7-point Likert scale with good internal reliability $(\alpha=0.843)$.

\section{Self-compassion scale (SCS- short form)}

The SCS short-form (Raes, Pommier, Neff, \& Van Gucht, 2011) measures the ability to approach one's suffering with warmth and concern. It has 12 items scored on a 5-point Likert scale, with good internal reliability $(\alpha=0.875)$.

\section{Psychological wellbeing autonomy subscale (APWB)}

The APWB is a 14-item subscale of the PWB scale (Ryff \& Keyes, 1995). It measures the respondents' ability to resist social pressures and remain independent, as well as their self-regulating capabilities. The scale is scored on a 6-point Likert scale with good internal reliability $(\alpha=0.898)$.

\section{Generalised self-efficacy scale (GSE)}

The GSE (Schwarzer \& Jerusalem, 1995) is a 10-item scale that measures perceived selfefficacy in dealing with stressors. It isscored on a 4-point Likert scale, with good internal reliability $(\alpha=0.896)$.

\section{Meaning in life questionnaire: presence subscale (MLQ-P)}

The MLQ-P (Steger et al., 2006) measures perceived presence of meaning in life. It comprises 5 items, scored on a 7-point Likert scale with good internal reliability $(\alpha=0.927)$.

\section{Compassion for others scale (COS)}

The 24-item CS (Pommier, 2011) measures compassion for others using three factors: kindness, common humanity and mindfulness. It is scored on a 5-point Likert scale with good internal reliability $(\alpha=0.875)$. 


\section{Appreciation inventory scale: present moment subscale (APM)}

The APM (Adler \& Fagley, 2005) measures the respondents' appreciation of their surroundings. It has 7 items, scored on a 7-point Likert scale with good internal reliability $(\alpha=0.905)$.

\section{Data Analyses}

The reliability of the scales at baseline was checked by using Cronbach's alpha coefficients. To examine whether randomisation achieved its purpose, independent samples t-tests (two-tailed) and chi squared tests were run to analyse differences in demographics and pre-test outcome results between the experimental and control groups.

Mixed-design Analyses of Variance (Split-plot ANOVAs or RM ANOVAS) were run on the pre and post scores of each scale, comparing the evolution of experimental and control groups over three points in time and examining the group $\times$ time interaction in a per protocol fashion. Additional independent samples t-tests were used as a way of illustrating static differences between the two groups over the follow up points. In order to carry out Intent-to-Treat analyses (Moher, Schultz, \& Altman, 2001), five multiple imputations were used to fill in for missing information on participants with at least baseline data. These imputations enabled mixed-design ANOVAs with three observations (ten in the case of the PHI experienced wellbeing subscale, in order to have an alternative unbiased version of figure 2 , see below).

RM ANCOVAS were used to analyse the effects of the meditation experience and of the frequency of meditation and daily practice as well as baseline wellbeing and depression on the evolution of outcomes. All analyses were completed with a significance of $\mathrm{p}<.05$, using SPSS 20 for Windows. 


\section{Results}

As outlined in Table 2, no significant differences were observed between the experimental and control groups, in terms of key socio-demographic variables. Regarding the differences between completers and non-completers, completers scored significantly higher on the FMI (Mindfulness, $\mathrm{t}=2.10, \mathrm{MD}=1.980, \mathrm{p}=.036$ ) and the COS (Compassion for others, $\mathrm{t}=2.269, \mathrm{MD}=1.874, \mathrm{p}=.024)$ in pre-tests, compared with non-completers. There were no significant differences on the other 10 scales. More control group participants completed (52\%), compared with experimental participants (24\%).

Table 2. Comparison of demographic characteristics and baseline psychometric measures between control and experimental groups

\begin{tabular}{|c|c|c|c|c|c|}
\hline \multirow[t]{2}{*}{ SOCIO-DEMOGRAPHICS } & \multicolumn{2}{|c|}{$\begin{array}{l}\text { Experimental } \\
(n=212)\end{array}$} & \multicolumn{2}{|c|}{$\begin{array}{l}\text { Control } \\
(\mathbf{n}=182)\end{array}$} & \multirow[b]{2}{*}{$\begin{array}{l}\text { Statistical } \\
\text { significance }\end{array}$} \\
\hline & $\mathbf{N}$ & $\%$ & $\mathbf{N}$ & $\%$ & \\
\hline Gender ( $\%$ female) & 163 & 76.9 & 147 & 80.8 & $\square^{2}=.880, \mathrm{p}=.348$ \\
\hline $\begin{array}{l}\text { Education } \\
\text { (University degree) }\end{array}$ & 164 & 77.4 & 140 & 76.9 & $\square^{2}=.011, \mathrm{p}=.918$ \\
\hline \multirow{2}{*}{$\begin{array}{l}\text { Income } \\
\text { (below Household Income } \\
\text { over } \$ 35 \text { k a year) }\end{array}$} & 105 & 49.5 & 95 & 52.2 & $\square^{2}=.279, \mathrm{p}=.597$ \\
\hline & M & $\underline{\mathrm{SD}}$ & $\underline{M}$ & $\underline{\mathrm{SD}}$ & \\
\hline Age & 41.31 & 11.51 & 40.32 & 11.08 & $\mathrm{t}=.864, \mathrm{p}=.388$ \\
\hline $\begin{array}{l}\text { Meditation Experience in } \\
\text { years }\end{array}$ & 2.80 & 3.04 & 2.58 & 2.77 & $\mathrm{t}=.751, \mathrm{p}=.453$ \\
\hline \multicolumn{6}{|l|}{ WELL-BEING } \\
\hline Stress (PSS) & 28.54 & 6.82 & 28.38 & 6.18 & $\mathrm{t}=.242, \mathrm{p}=.809$ \\
\hline Depression (BDI-II) & 13.46 & 9.48 & 12.55 & 8.58 & $\mathrm{t}=.982, \mathrm{p}=.327$ \\
\hline Well-Being (PHI - PIS) & 6.44 & 1.74 & 6.36 & 1.76 & $t=.435, p=.664$ \\
\hline Mindfulness (FMI) & 33.08 & 7.71 & 34.23 & 8.26 & $\mathrm{t}=-1.428, \mathrm{p}=.154$ \\
\hline Gratitude (GQ6) & 35.15 & 5.85 & 35.04 & 5.59 & $\mathrm{t}=.181, \mathrm{p}=.856$ \\
\hline Self-Compassion (SCS) & 3.02 & 0.73 & 3.05 & 0.80 & $\mathrm{t}=-.358, \mathrm{p}=.720$ \\
\hline Self-Efficacy (GSE) & 30.65 & 4.50 & 30.58 & 4.39 & $\mathrm{t}=.844, \mathrm{p}=.399$ \\
\hline Autonomy (APWB) & 57.98 & 12.08 & 56.91 & 12.56 & $\mathrm{t}=.319, \mathrm{p}=.750$ \\
\hline Meaning (MLQP) & 23.70 & 6.92 & 23.77 & 7.22 & $\mathrm{t}=-.096, \mathrm{p}=.924$ \\
\hline Positive Relations (COS) & 70.48 & 9.14 & 71.52 & 8.75 & $\mathrm{t}=-1.123, \mathrm{p}=.262$ \\
\hline Engagement (APM) & 39.59 & 7.01 & 38.99 & 7.97 & $\mathrm{t}=.765, \mathrm{p}=.445$ \\
\hline
\end{tabular}


In our study all scales showed good internal reliability, with Cronbach alphas ranging from 0.816 to 0.927 (see above in the description of the scales for exact values). Table 2 shows pre-test scores of the 11 scales. There was no significant difference between the experimental group and control group in any of the scales.

After the intervention, all outcomes showed statistically significant mean differences between the experimental and control group (see table 3). These differences persisted one month following intervention completion for all the measures except the GSE (Self-Efficacy). Statistically significant group $x$ time interactions within the RM ANOVAS were found in all outcomes except for the APWB (Autonomy), GSE (SelfEfficacy), and COS (Compassion for others) with low to moderate effect sizes. With regard to the slope of wellbeing, the gains of the experimental group remained constant on the PHI-EW (Experienced wellbeing) subscale one month after the intervention, as illustrated in Figure 2. The operations carried out in an "intent to treat" fashion (i.e. with imputed data) showed differences in the "per protocol" analyses of only 13 of the total 55 scenarios. Diverging results were noticed in one of the five imputations for the PHI (Wellbeing, with no interaction found), five for the GQ6 (Gratitude, idem), one for the SCS (Self-compassion, idem), one for the MLQ-P (Meaning in life, with no interaction found) two for the COS (Compassion for others, with interaction) and three for the APM (Appreciation, with interaction found). 
Table 3. Measurement results of all scales comparing experimental and control groups

\begin{tabular}{|c|c|c|c|c|c|c|c|c|c|c|c|c|c|c|c|c|c|c|c|}
\hline \multicolumn{8}{|c|}{ Post-test } & \multicolumn{8}{|c|}{1 Month Post-test } & \multirow{2}{*}{\multicolumn{4}{|c|}{$\begin{array}{c}\text { Group } x \text { time interactions } \\
\begin{array}{c}\text { (Greenhouse- Geisser interaction of } \\
\text { outcomes with group) }\end{array}\end{array}$}} \\
\hline & \multicolumn{2}{|c|}{$\begin{array}{l}\text { Experiment al } \\
\quad(n=53)\end{array}$} & \multicolumn{2}{|c|}{$\begin{array}{l}\text { Control } \\
(n=115)\end{array}$} & \multicolumn{3}{|c|}{$\begin{array}{c}\text { Mean difference } \\
\text { statistical significance }\end{array}$} & \multicolumn{2}{|c|}{$\begin{array}{l}\text { Experime ntal } \\
\quad(n=35)\end{array}$} & \multicolumn{2}{|c|}{$\begin{array}{c}\text { Control } \\
(n=43)\end{array}$} & \multicolumn{4}{|c|}{$\begin{array}{c}\text { Mean difference } \\
\text { statistical significance }\end{array}$} & & & & \\
\hline & $\mathbf{M}$ & SD & $\mathbf{M}$ & SD & $\mathbf{t}$ & df & $\mathbf{p}$ & M & SD & M & SD & & $\mathbf{t}$ & df & $\mathbf{p}$ & $\mathbf{F}$ & d f & $\mathbf{p}$ & $\eta p 2$ \\
\hline PSS & $\begin{array}{r}22 . \\
45\end{array}$ & $\begin{array}{c}5.4 \\
5\end{array}$ & $\begin{array}{r}26 . \\
92\end{array}$ & $\begin{array}{c}7.3 \\
1\end{array}$ & $\begin{array}{c}- \\
4 . \\
39\end{array}$ & $\begin{array}{r}13 \\
2.7\end{array}$ & $\begin{array}{c}<.00 \\
01\end{array}$ & $\begin{array}{l}19 . \\
35\end{array}$ & $\begin{array}{c}5.6 \\
6\end{array}$ & $\begin{array}{r}25 . \\
15\end{array}$ & $\begin{array}{c}6.4 \\
6\end{array}$ & $\begin{array}{c}6.4 \\
6\end{array}$ & $\begin{array}{c}- \\
3.6 \\
3\end{array}$ & $\begin{array}{r}58 \\
.0\end{array}$ & $\begin{array}{l}<.0 \\
01\end{array}$ & $\begin{array}{c}8.6 \\
2\end{array}$ & $\begin{array}{r}1 \\
.8\end{array}$ & $\begin{array}{c}<.00 \\
1\end{array}$ & $\begin{array}{l}.1 \\
10\end{array}$ \\
\hline $\begin{array}{c}\text { BDI- } \\
\text { II }\end{array}$ & $\begin{array}{c}4.7 \\
2\end{array}$ & $\begin{array}{c}5.3 \\
8\end{array}$ & $\begin{array}{c}11 . \\
36\end{array}$ & $\begin{array}{c}10 . \\
18\end{array}$ & $\begin{array}{l}- \\
5 . \\
52\end{array}$ & $\begin{array}{r}16 \\
2.9\end{array}$ & $\begin{array}{c}<.00 \\
01\end{array}$ & $\begin{array}{c}3.5 \\
0\end{array}$ & $\begin{array}{c}3.4 \\
4\end{array}$ & $\begin{array}{c}11 . \\
70\end{array}$ & $\begin{array}{c}8.7 \\
7\end{array}$ & $\begin{array}{c}8.7 \\
7\end{array}$ & $\begin{array}{c}- \\
5.2 \\
4\end{array}$ & $\begin{array}{r}54 \\
.3\end{array}$ & $\begin{array}{c}<.0 \\
001\end{array}$ & $\begin{array}{c}8.6 \\
2\end{array}$ & $\begin{array}{r}1 \\
.8\end{array}$ & $\begin{array}{c}<.00 \\
1\end{array}$ & $\begin{array}{c}.1 \\
10\end{array}$ \\
\hline PHI & $\begin{array}{c}7.8 \\
1\end{array}$ & $\begin{array}{c}1.2 \\
3\end{array}$ & $\begin{array}{c}6.6 \\
6\end{array}$ & $\begin{array}{r}1.9 \\
4\end{array}$ & $\begin{array}{c}4 . \\
65\end{array}$ & $\begin{array}{r}14 \\
9.4\end{array}$ & $\begin{array}{c}<.00 \\
01\end{array}$ & $\begin{array}{c}8.2 \\
8\end{array}$ & $\begin{array}{c}1.3 \\
8\end{array}$ & $\begin{array}{c}6.7 \\
6\end{array}$ & $\begin{array}{c}1.7 \\
7\end{array}$ & $\begin{array}{c}1.7 \\
7\end{array}$ & $\begin{array}{c}4.2 \\
6\end{array}$ & $\begin{array}{r}75 \\
.9\end{array}$ & $\begin{array}{c}<.0 \\
001\end{array}$ & $\begin{array}{r}10 . \\
62\end{array}$ & $\begin{array}{l}1 \\
8\end{array}$ & $\begin{array}{c}<.00 \\
01\end{array}$ & $\begin{array}{r}.1 \\
24\end{array}$ \\
\hline FMI & $\begin{array}{l}40 . \\
96\end{array}$ & $\begin{array}{c}7.3 \\
2\end{array}$ & $\begin{array}{l}36 . \\
09\end{array}$ & $\begin{array}{r}8.7 \\
7\end{array}$ & $\begin{array}{c}3 . \\
52\end{array}$ & $\begin{array}{r}16 \\
6.0\end{array}$ & $\begin{array}{c}<.00 \\
1\end{array}$ & $\begin{array}{r}43 . \\
49\end{array}$ & $\begin{array}{c}6.3 \\
0\end{array}$ & $\begin{array}{l}37 . \\
30\end{array}$ & $\begin{array}{c}8.1 \\
6\end{array}$ & $\begin{array}{c}8.1 \\
6\end{array}$ & $\begin{array}{c}3.6 \\
8\end{array}$ & $\begin{array}{r}76 \\
.0\end{array}$ & $\begin{array}{l}<.0 \\
001\end{array}$ & $\begin{array}{r}16 . \\
22\end{array}$ & $\begin{array}{r}1 \\
.8\end{array}$ & $\begin{array}{c}<.00 \\
01\end{array}$ & $\begin{array}{l}.1 \\
76\end{array}$ \\
\hline GQ6 & $\begin{array}{c}38 . \\
54\end{array}$ & $\begin{array}{c}4.1 \\
5\end{array}$ & $\begin{array}{r}35 . \\
01\end{array}$ & $\begin{array}{c}6.5 \\
3\end{array}$ & $\begin{array}{l}4 . \\
04\end{array}$ & $\begin{array}{r}14 \\
0.1\end{array}$ & $\begin{array}{c}<.00 \\
01\end{array}$ & $\begin{array}{l}39 . \\
96\end{array}$ & $\begin{array}{c}3.2 \\
2\end{array}$ & $\begin{array}{l}35 . \\
35\end{array}$ & $\begin{array}{c}6.0 \\
1\end{array}$ & $\begin{array}{c}6.0 \\
1\end{array}$ & $\begin{array}{c}3.8 \\
1\end{array}$ & $\begin{array}{r}52 \\
.6\end{array}$ & $\begin{array}{c}<.0 \\
001\end{array}$ & $\begin{array}{c}5.2 \\
4\end{array}$ & 2 & $\begin{array}{c}<.00 \\
5\end{array}$ & $\begin{array}{r}.0 \\
83\end{array}$ \\
\hline SCS & $\begin{array}{c}3.6 \\
4\end{array}$ & $\begin{array}{r}0.7 \\
4\end{array}$ & $\begin{array}{c}3.1 \\
6\end{array}$ & $\begin{array}{c}0.8 \\
7\end{array}$ & $\begin{array}{c}3 . \\
52\end{array}$ & $\begin{array}{l}11 \\
0.1\end{array}$ & $\begin{array}{c}<.00 \\
1\end{array}$ & $\begin{array}{c}4.0 \\
0\end{array}$ & $\begin{array}{c}0.7 \\
0\end{array}$ & $\begin{array}{c}3.4 \\
3\end{array}$ & $\begin{array}{c}0.8 \\
1\end{array}$ & $\begin{array}{c}0.8 \\
1\end{array}$ & $\begin{array}{c}2.8 \\
6\end{array}$ & $\begin{array}{r}58 \\
.0\end{array}$ & $\begin{array}{c}.00 \\
6\end{array}$ & $\begin{array}{c}11 . \\
24\end{array}$ & $\begin{array}{r}1 \\
6\end{array}$ & $\begin{array}{c}<.00 \\
01\end{array}$ & $\begin{array}{c}.1 \\
65\end{array}$ \\
\hline GSE & $\begin{array}{c}33 . \\
66\end{array}$ & $\begin{array}{c}3.6 \\
3\end{array}$ & $\begin{array}{c}31 . \\
64\end{array}$ & $\begin{array}{r}5.1 \\
2\end{array}$ & $\begin{array}{c}2 . \\
50\end{array}$ & $\begin{array}{c}15 \\
0.0\end{array}$ & .013 & $\begin{array}{c}36 . \\
31\end{array}$ & $\begin{array}{c}3.6 \\
9\end{array}$ & $\begin{array}{c}34 . \\
82\end{array}$ & $\begin{array}{c}5.5 \\
2\end{array}$ & $\begin{array}{c}5.5 \\
2\end{array}$ & $\begin{array}{c}1.2 \\
5\end{array}$ & $\begin{array}{r}57 \\
.1\end{array}$ & $\begin{array}{c}.21 \\
8\end{array}$ & $\begin{array}{c}1.0 \\
3\end{array}$ & $\begin{array}{r}1 \\
.5\end{array}$ & .343 & $\begin{array}{r}.0 \\
18\end{array}$ \\
\hline $\begin{array}{r}\text { AP } \\
\text { WB }\end{array}$ & $\begin{array}{c}64 . \\
76\end{array}$ & $\begin{array}{l}10 . \\
35\end{array}$ & $\begin{array}{c}58 . \\
58\end{array}$ & $\begin{array}{l}13 . \\
27\end{array}$ & $\begin{array}{c}3 . \\
14\end{array}$ & $\begin{array}{c}12 \\
1.6\end{array}$ & .002 & $\begin{array}{c}62 . \\
67\end{array}$ & $\begin{array}{c}13 . \\
02\end{array}$ & $\begin{array}{c}53 . \\
38\end{array}$ & $\begin{array}{l}10 . \\
45\end{array}$ & $\begin{array}{r}10 . \\
45\end{array}$ & $\begin{array}{c}2.5 \\
6\end{array}$ & $\begin{array}{r}30 \\
.3\end{array}$ & $\begin{array}{c}.01 \\
6\end{array}$ & $\begin{array}{c}2.7 \\
8\end{array}$ & $\begin{array}{r}1 \\
.9\end{array}$ & .071 & $\begin{array}{r}.0 \\
58\end{array}$ \\
\hline $\begin{array}{c}\text { ML } \\
\text { QP }\end{array}$ & $\begin{array}{c}29 . \\
32\end{array}$ & $\begin{array}{c}4.7 \\
0\end{array}$ & $\begin{array}{c}23 . \\
73\end{array}$ & $\begin{array}{c}8.2 \\
3\end{array}$ & $\begin{array}{c}5 . \\
32\end{array}$ & $\begin{array}{r}14 \\
6.5\end{array}$ & $\begin{array}{c}<.00 \\
01\end{array}$ & $\begin{array}{r}29 . \\
84\end{array}$ & $\begin{array}{c}5.4 \\
1\end{array}$ & $\begin{array}{r}25 . \\
15\end{array}$ & $\begin{array}{c}6.7 \\
2\end{array}$ & $\begin{array}{c}6.7 \\
2\end{array}$ & $\begin{array}{c}2.8 \\
6\end{array}$ & $\begin{array}{r}56 \\
.0\end{array}$ & $\begin{array}{c}.00 \\
6\end{array}$ & $\begin{array}{c}5.3 \\
8\end{array}$ & $\begin{array}{r}1 \\
.8\end{array}$ & $<.01$ & $\begin{array}{r}.0 \\
88\end{array}$ \\
\hline $\cos$ & $\begin{array}{c}75 . \\
19\end{array}$ & $\begin{array}{c}7.0 \\
9\end{array}$ & $\begin{array}{c}70 . \\
66\end{array}$ & $\begin{array}{l}10 . \\
28\end{array}$ & $\begin{array}{c}3 . \\
17\end{array}$ & $\begin{array}{r}13 \\
3.4\end{array}$ & .002 & $\begin{array}{c}76 . \\
09\end{array}$ & $\begin{array}{c}8.4 \\
9\end{array}$ & $\begin{array}{c}69 . \\
78\end{array}$ & $\begin{array}{c}9.1 \\
7\end{array}$ & $\begin{array}{c}9.1 \\
7\end{array}$ & $\begin{array}{c}2.6 \\
8\end{array}$ & $\begin{array}{r}56 \\
.0\end{array}$ & $\begin{array}{c}.01 \\
0\end{array}$ & $\begin{array}{c}2.3 \\
8\end{array}$ & $\begin{array}{r}1 \\
.9\end{array}$ & .1 & $\begin{array}{r}.0 \\
41\end{array}$ \\
\hline $\begin{array}{c}\mathbf{A P} \\
\mathbf{M}\end{array}$ & $\begin{array}{r}45 . \\
40\end{array}$ & $\begin{array}{c}4.2 \\
2\end{array}$ & $\begin{array}{l}39 . \\
72\end{array}$ & $\begin{array}{c}8.7 \\
5\end{array}$ & $\begin{array}{c}5 . \\
40\end{array}$ & $\begin{array}{c}15 \\
0.0\end{array}$ & $\begin{array}{c}<.00 \\
01\end{array}$ & $\begin{array}{c}46 . \\
00\end{array}$ & $\begin{array}{c}4.6 \\
4\end{array}$ & $\begin{array}{c}41 . \\
91\end{array}$ & $\begin{array}{c}6.0 \\
3\end{array}$ & $\begin{array}{c}6.0 \\
3\end{array}$ & $\begin{array}{c}2.8 \\
0\end{array}$ & $\begin{array}{r}55 \\
.0\end{array}$ & $\begin{array}{c}.00 \\
7\end{array}$ & $\begin{array}{c}3.4 \\
9\end{array}$ & $\begin{array}{r}1 \\
.7\end{array}$ & $<.05$ & $\begin{array}{l}.0 \\
60\end{array}$ \\
\hline
\end{tabular}


Figure 2. Evolution of the PHI (Pamberton Happiness Index) in the experimental group using PP(Per Protocol, available data, left) and ITT (Intent to Treat, imputed, right) approaches
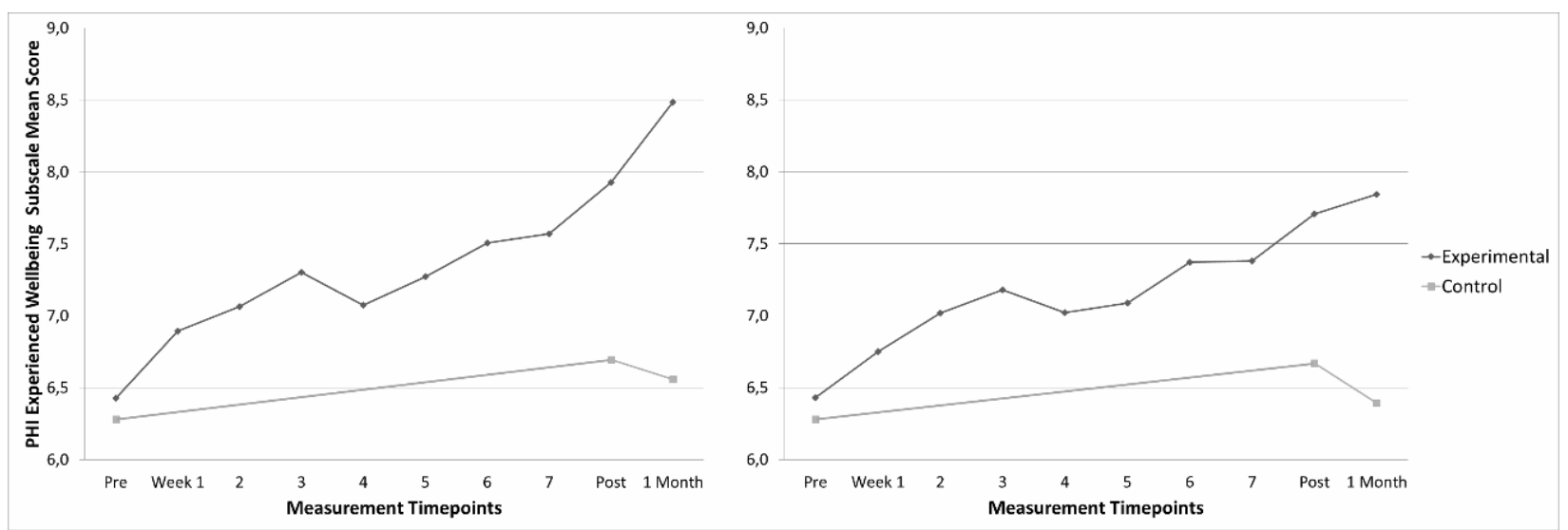

Participants had been meditating for an average of 2.69 years, spent an average of 17.14 minutes meditating per day during the intervention, and the mean practice during the study was 39 days with a similar amount of average completed meditations. After controlling for these four variables (previous meditation experience, baseline weekly meditation hours, meditation frequency and practice over the study period), no difference was found in the RM ANCOVA results and the split-plot ANOVAS, with just the condition as factor. The duration of the participants' previous meditation experience did statistically significantly covariate with the slope of stress (PSS; F=3.254, p<.05, $\eta \mathrm{p} 2=.056$ ) and mindfulness (FMI; F=3.640, $\mathrm{p}<.05, \eta \mathrm{p} 2=.047$ ); and the weekly hours meditating covariated with autonomy (APWB; F=3.771, $\mathrm{p}<.05, \eta p 2=.081$ ). The frequency of completed meditation and daily practice significantly covariated (very strongly) with the slope of appreciation (APM; meditations: $F=21.282, \mathrm{p}<.0001$, $\eta p 2=.492$, practices: $\mathrm{F}=12.294, \mathrm{p}<.0001, \eta \mathrm{p} 2=.358)$. 
Further RM ANCOVAS revealed that BDI-II and PHI scores co-variated significantly with scores such as the PSS (BDI; F=4.993, p<.05, ๆp2=.083), FMI (BDI; $\mathrm{F}=4.575, \mathrm{p}<.05, \eta \mathrm{p} 2=.058)$, APWB (BDI; F=5.236, $\mathrm{p}<.01, \eta \mathrm{p} 2=.109)$, MLQ-P (BDI; $\mathrm{F}=10.275, \mathrm{p}<.0001, \eta \mathrm{p} 2=.160)$, and APM (BDI; $\mathrm{F}=4.408, \mathrm{p}<.05, \eta \mathrm{p} 2=.077)$. No statistically significant co-variation was found for the PHI baseline scores.

\section{Discussion}

The present study has yielded important findings, indicating that the PMP was able to boost wellbeing which paves the way for future research in this area. The study demonstrates the efficacy of this new type of intervention by confirming the two hypotheses made at its outset. Participation in the PMP led to statistically significantly higher post-test results on all the scales in the experimental group, compared with the control group. More specifically, participants exhibited increases in nine measures (positive emotions, self-compassion, happiness, autonomy, mindfulness, self-efficacy, meaning, compassion to others, and savouring) and decreases in the other two (stress and depression). These changes were still found with participants who completed the intervention in a one-month follow-up, in 10 out of the 11 measures. Longitudinal analyses yielded statistically significant differences in the slope of the mean evolutions in 8 out of the 11 measures, confirming the longitudinal impact.

The PMP was also found to be feasible with participants with mild levels of depression, constituting the baseline level of the latter a covariate of the improvement in various parameters. These results further substantiated previous findings that indicated the existence of a link between mindfulness and positive variables. The results evidenced the capacity of mindfulness-based programs to significantly promote positive change. They also suggested that PMP could complement the currently used deficit-focused programs, and could be used as an alternative method of studying the way mindfulness could lead to greater wellbeing. 
The structure of the PMP has proven effective; a daily practice interweaving PPIs and mindfulness has shown an ability to produce the desired effect. The positive mindfulness cycle could be a promising theoretical framework for the point of convergence between the two disciplines of PP and mindfulness. The IAA model of mindfulness (Shapiro et al., 2006) and the experience of savouring (Bryant \& Veroff, 2007) were used to integrate the PMP components, and to explain the program's mechanism. The PPIs intentions set the stage for mindfulness, which, in turn, allowed boosted savouring of the PPIs, thus creating a cyclic process enhancing wellbeing. The results of this study supported the idea that, once strengths and virtues are set as the intention of the practice, and are followed by mindfulness and savouring, an increase can be achieved in a variety of wellbeing variables.

The results also showed that in ten of the eleven measures the improvement persisted one month after the program's completion. This indicated that the impact of the program does not fade away with the end of practice, allowing participants to benefit from a ripple effect of enhanced wellbeing for at least a month following the program. Longitudinal studies are scarce and much needed in positive psychology research (Avey, Luthans \& Mhatre, 2008). The results of the present study with their variety of enhanced wellbeing variables, are a valuable contribution to the positive psychology literature.

The effectiveness of the PMP is further exemplified by the weekly increase in wellbeing noticed in the experimental group, as seen in the constant gains on the PHIEW (Experienced wellbeing) Subscale. These gains persisted a month after the intervention's completion, and were shown for imputed data (which could be considered a more conservative approach) as well. Significant interactions were also found between most of the outcomes, with the exception of Autonomy, Self-Efficacy, and Compassion for others and in all of the imputed versions of the Gratitude scale. These results indicated a lasting effect in most variables; the effect was not transient, and the evolution of 
improvement continuously increased.

The potential of the PMP is particularly striking considering that the program is well suited for replication on a larger scale. Because it is delivered online, the program may be scaled-up to include large populations worldwide. It is inexpensive to deliver, and requires dedicating no more than 12 minutes a day. Online delivery also means the program does not require a trained facilitator, and could be delivered to people in the familiar settings of their own homes (Krusche, Cyhlarova \& Williams, 2012).

Delivering the PMP to large and varied populations is of particular importance, given that one of the most impressive improvements introduced by the program was in the levels of depression. Baseline levels of depression co-variated significantly with the measures of Perceived Stress, Mindfulness, Autonomy, Meaning, and Present Moment Appreciation, partially confirming the secondary hypothesis. These results are in line with the meta-analysis conducted by Sin and Lyubomirsky (2009), which examined 25 separate studies on the influence of PPIs on depression. According to the findings of the meta-analysis, depressed participants gained more from the PPIs than non-depressed participants did. The conclusions of the present study support the idea (Fava et al., 2005) that PP may also be suitable for individuals with psychological difficulties. The PMP could assist in dealing with depression by shifting people from 'languishing' towards 'flourishing' on the mental health continuum (Keyes, 2002). Online inexpensive programs such as the PMP are able to assist over-burdened health care systems (Krusche et al., 2012), where people go untreated due to the high cost of other interventions (Layous, Chancellor, Lyubomirsky, Wang \& Doraiswamy, 2011). Future research could test the specific efficacy of the PMP in depressed individuals.

The PMP was developed to complement existing mindfulness programs, and it would be interesting to make a comparison between them. Grossman et al. (2004) conducted a meta-analysis of randomised controlled trials of MBSR programs which 
revealed effect sizes for wait-list studies similar to the present one of $d=0.49,0.67,0.62$, and $0.54(r=0.24,0.32,0.3$ and 0.26 , respectively), including the measures of mental health and psychological wellbeing. In relation to differences in the evolution of control and intervention groups, the PMP effect size was $r=.35\left(\eta p^{2}=0.124\right)$ for wellbeing on the PHI. A randomised control trial would be useful to thoroughly compare the PMP with existing mindfulness programs. This is a potential future research direction. One possible PMP advantage worth exploring is its ability to offer support without pathologisation, much like other PPIs, reducing stigma and thus being more appealing to the general population.

Another direction for future research could be exploring the underlying mechanisms of PMP-induced positive change. The results of the present study indicate that the number of times the participants completed the meditations and the daily practices had little effect on their gains. The frequency of practice only covariated with the APM. This result is different from those of other studies, where extended practice increased the effects of mindfulness interventions (e.g., Carmody \& Baer, 2008). This raised questions about the way the program worked. We tended to assume that in the present study informal practice had a greater impact than formal practice. The videos, meditations and daily practice that were part of the intervention protocol, instructed the participants to apply the knowledge and skills they acquired to their everyday life. The implementation of the intervention materials in the participant's daily interactions and events may have had a greater influence than the daily "formal" meditation and subsequent practice. This seems even more probable if we consider that the participants were told not to advance to the materials of the next week until they had engaged at least once with the video, meditation and practice of that week, and applied them within a seven-day framework.

It is recommended to incorporate a measure of informal practice in future studies, in which the participants will be asked to report at the end of every day how many times 
they applied the intervention's practice in their experiences of that day. A qualitative research element may also be added to future studies, to assist in deeper understanding of the participants' experiences and the mechanisms behind the intervention's success.

Online mindfulness programs have proven effective (Krusche et al., 2012). The need for online mindfulness programs stems from patients' requirement for a flexible delivery method and mental health systems which are under heavy pressure to deliver more for less (Kuyken, 2011). Therefore, online mindfulness programs would benefit a large number of people, who otherwise could not have joined such courses (Beattie, Shaw $\&$ Kaur, 2009). These courses have delivered promising results, proving to be of great benefit to patients with a range of disorders (Hollandare, Johnson \& Randestad, 2011). At the same time, delivering the PMP in person could prove a valuable avenue of investigation as in-person delivery may reduce attrition rates. It would also help provide psychological support during the intervention that would be particularly valuable in studying the effect of the PMP on depressed populations.

\section{Limitations}

Several limitations of the PMP must be acknowledged. First, although the groups were equal in size at the outset of the program, because of the high attrition rate, the control group $(\mathrm{N}=115)$ was considerably larger than the experimental group $(\mathrm{N}=53)$ upon completion. This point could be addressed by closer monitoring and implementing measures to increase motivation in the control group. At the applied level, without the limitations and rigidity required for a randomised controlled trial, meditation would be practiced with a more flexible schema where people can practise with varying degrees of intensity. Another apparent limitation is the program's complete reliance on self-report scales, which are vulnerable to social desirability response bias. While it is unlikely that this accounts for all significant results, this latent risk could be overcome by conducting 
future studies with active controls or with objective measures such as physical health or behaviour. External validity was strong as participants received the program online in much the same way it would be delivered to a general population audience. The participating population was mixed in terms of age, income, and location, which enhances generalisability. However, the participants were predominantly highly-educated females, and although they came from twenty countries the majority were from English-speaking Western cultures. Further studies with different populations could yield more inclusive results. Treatment expectancy could not be ruled out as no specific scale was added to the baseline measures package. However, the inclusion of a group of people practising meditation gave us an idea of the differential effect of the PMP on people with previous experience. Finally, the current study did not evaluate whether participants had a current meditation or yoga practice, which could have been an influencing factor. Future studies should address this issue and examine the impact of this potential variable.

A concern to be tackled is that the positive mindfulness cycle might generate an attachment to pleasant or positive experiences, leading to potential suffering when the experience unavoidably disappears (Garland et al., 2015). Addressing this concern, Wallace and Shapiro (2006) state: “A common misperception is that Buddhism uniformly denies the value of stimulus-driven pleasures, as if it were morally wrong to enjoy the simple pleasures of life, let alone the joys of raising a family, creating fine works of art, or making scientific discoveries... The enjoyment of such transient experiences is not in opposition to the cultivation of positive attitudes and commitments or the cultivation of the types of mental balance that yield inner well-being" (p. 692). Mindfulness practice allows the cultivation of a non-attached, open relationship with experiences, thereby strengthening the practitioner's capacity to let go of any potential attachment as part of the positive mindfulness cycle. Mindfulness practice does not happen in a vacuum; therefore, having intentions or savouring experiences is a natural part of the practice. According to 
Carlson (2015), this is not a concern, as long as the intentions and savouring are accompanied and balanced by equanimity and non-attachment. In fact, Carlson (2015) believes that the awareness of impermanence infuses beauty and non-attached joy in savouring and intentions because the practitioner knows they will fade away and change.

\section{Compliance with Ethical Standards}

Conflict of Interest: The authors declare that they have no conflict of interest.

\section{References}

Adler, M. G., \& Fagley, N. S. (2005). Appreciation: Individual Differences in Finding Value and Meaning as a Unique Predictor of Subjective Well-Being. Journal of personality, 73(1), 79-114.

Avey, J. B., Luthans, F., \& Mhatre, K. H. (2008). A call for longitudinal research in positive organizational behavior. Journal of Organizational Behavior, 29(5), 705711.

Beck, A. T., Steer, R. A., Ball, R., \& Ranieri, W. F. (1996). Comparison of Beck Depression Inventories-IA and -II in Psychiatric Outpatients. Journal of Personality Assessment, 67(3), 588-97.

Baer, R. A., Lykins, E. L. B., \& Peters, J. R. (2012). Mindfulness and self-compassion as predictors of psychological wellbeing in long-term meditators and matched non-meditators. Journal of Positive Psychology, 7(3), 230-238.

Beattie, A., Shaw, A., \& Kaur, S. (2009). Primary-care patients' expectations and experiences of online cognitive behavioural therapy for depression: a qualitative study. Health Expect, 12(1), 45-59.

Bishop, S. R., Lau, M., Shapiro, S., Carlson, L., Anderson, N. D., Carmody, J., Segal, Z. V., Abbey, S., Speca, M., Velting, D., \& Devins, G. (2004). Mindfulness : A Proposed Operational Definition. Clinical psychology: Science and practice, 11(3), 230-241.

Brown, K. W., \& Cordon, S. (2009). Toward a phenomenology of mindfulness: Subjective experience and emotional correlates. In F. Didonna (Ed.) Clinical handbook of mindfulness, (pp. 59-81). New-York: Springer.

Brown, K. W., \& Ryan, R. M. (2003). The benefits of being present: Mindfulness and its role in psychological well-being. Journal of Personality and Social 
Psychology, 84(4), 822-848.

Brown, K. W., Ryan, R. M., \& Creswell, J. D. (2007). Mindfulness: Theoretical Foundations and Evidence for its Salutary Effects. Psychological Inquiry, 18(4), 211-237.

Bryant, F. B., \& Veroff, J. (2007). Savoring: A new model of positive experience.

Mahwah, NJ: Lawrence Erlbaum Associates, Inc.

Carlson, L. E. (2015). The Mindfulness-to-Meaning Theory: Putting a Name to Clinical Observations. Psychological Inquiry, 26(4), 322-325.

Carmody, J., \& Baer, R. A. (2008). Relationships between mindfulness practice and levels of mindfulness, medical and psychological symptoms and well-being in a mindfulness-based stress reduction program. Journal of behavioral medicine, 31(1), 23-33.

Cohen, S., \& Williamson, G. (1988). Perceived stress in a probability sample of the United States. In S. Spacapan \& S. Oskamp (Eds.), The social psychology of health: Claremont Symposium on applied social psychology, (pp. 31-67).

Newbury Park, CA: Sage.

Deci, E. L., \& Ryan, R. M. (2008). Hedonia, eudaimonia, and well-being: An introduction. Journal of Happiness Studies, 9(1), 1-11.

Fredrickson, B. L., Cohn, M. A., Coffey, K. A., Pek, J., \& Finkel, S. M. (2008). Open hearts build lives: positive emotions, induced through loving-kindness meditation, build consequential personal resources. Journal of Personality and Social Psychology, 95(5), 1045-1062.

Frijda, N. H., \& Sundararajan, L. (2007). Emotion refinement: A theory inspired by Chinese poetics. Perspectives on Psychological Science, 2(3), 227-241.

Garland E. L., Farb, N. A., Goldin, P., \& Fredrickson, B. L. (2015). Mindfulness Broadens Awareness and Builds Eudaimonic Meaning at the AttentionAppraisal-Emotion Interface: A Process Model of Mindful Positive Emotion Regulation. Psychological Inquiry, 26(4), 293-314.

Geschwind, N., Peeters, F., Drukker, M., Van Os, J., \& Wichers, M. (2011). Mindfulness training increases momentary positive emotions and reward experience in adults vulnerable to depression: A randomized controlled trial. Journal of Consulting and Clinical Psychology, 79(5), 618-628.

Goldin, P. R. \& Gross, J. J. (2010). Effects of mindfulness-based stress reduction Page 30 de 34 
(MBSR) on emotion regulation in social anxiety disorder. Emotion, 10, 83-91.

Goleman, D. (2006). Social intelligence: The new science of human relationships. New York: Bantam.

Goyal, M., Singh, S., Sibinga, E. M., Gould, N. F., Rowland-Seymour, A., Sharma, R., et al. (2014). Meditation programs for psychological stress and well-being: a systematic review and meta-analysis. JAMA Internal Medicine, 174(3), 357-68.

Grossman, P., Niemann, L., Schmidt, S., \& Walach, H. (2004). Mindfulness-based stress reduction and health benefits. A meta-analysis. Journal of psychosomatic research, 57(1), 35-43.

Hanley, A. W., \& Garland, E. L. (2014). Dispositional mindfulness co-varies with selfreported positive reappraisal. Personality and Individual Differences, 66(1), 146152.

Hart, R., Ivtzan, I., \& Hart, D. (2013). Mind the gap in mindfulness research: A comparative account of the leading schools of thought. Review of General Psychology, 17(4), 453-466.

Heiman, J. R., \& Meston, C. M. (1997). Empirically validated treatment for sexual dysfunction. Annual Review of Sex Research, 8, 148-194.

Hervás, G., \& Vázquez, C. (2013). Construction and validation of a measure of integrative well-being in seven languages: The Pemberton Happiness Index. Health and quality of life outcomes, 11(1), 66.

Hollandare, F., Johnsson, S., \& Randestad, M., (2011). Randomized trial of Internetbased relapse prevention for partially remitted depression. Acta Psychiatr Scand, 124(4), 285-94.

Hölzel, B. K., Lazar, S. W., Gard, T., Schuman-Olivier, Z., Vago, D. R., \& Ott, U. (2011). How Does Mindfulness Meditation Work? Proposing Mechanisms of Action from a Conceptual and Neural Perspective. Perspectives on Psychological Science, 6(6), 537-559.

Hong, P. Y., Lishner, D. A., \& Han, K. H. (2014). Mindfulness and eating: An experiment examining the effect of mindful raisin eating on the enjoyment of sampled food. Mindfulness, 5(1), 80-87.

Ivtzan, I., \& Lomas, T. (2016). Mindfulness in Positive Psychology: The Science of Meditation and Wellbeing. London: Routledge. 
Kabat-Zinn, J. (1982). An outpatient program in behavioral medicine for chronic pain patients based on the practice of mindfulness meditation: Theoretical considerations and preliminary results. General Hospital Psychiatry, 4(1), 33-47.

Kabat-Zinn, J. (1990). Full catastrophe living: The program of the stress reduction clinic at the University of Massachusetts Medical Center. New York: Delta.

Kashdan, T. B., Rottenberg, J., Goodman, F. R., Disabato, D. J., \& Begovic, E. (2015). Lumping and Splitting in the Study of Meaning in Life: Thoughts on Surfing, Surgery, Scents, and Sermons. Psychological Inquiry, 26(4), 336-342.

Keyes, C. L. (2002). The mental health continuum: From languishing to flourishing in life. Journal of Health and Social Behavior, 43(2), 207-222.

Killingsworth, M. A., \& Gilbert, D. T. (2010). A wandering mind is an unhappy mind. Science, 330(6006), 932.

King, A. (2001). The health benefits of writing about life goals. Personality and Social Psychology Bulletin, 27(7), 798-807.

Krishnamurti, J. (1975). Freedom from the known. London: HarperOne.

Krusche, A., Cyhlarova, E., King, S., \& Williams, J. M. G. (2012). Mindfulness online: a preliminary evaluation of the feasibility of a web-based mindfulness course and the impact on stress. British Medical Journal, 2(3), e000803.

Kuyken, W. (2011). Mindfulness Training in the UK. Reykjavik, Iceland: $41^{\text {st }}$ Annual European Association for Behavioural and Cognitive Therapies (EABCT) Conference.

Layous, K., Chancellor, J., Lyubomirsky, S., Wang, L., \& Doraiswamy, P. (2011).

Delivering happiness: Translating positive psychology intervention research for treating major and minor depressive disorders. The Journal of Alternative And Complementary Medicine, 17(8), 675-683.

Lindsay, E. K., \& Creswell, J. D. (2015). Back to the Basics: How Attention Monitoring and Acceptance Stimulate Positive Growth. Psychological Inquiry, 26(4), 343348.

Lomas, T., Hefferon, K. \& Ivtzan, I. (2014). Applied Positive Psychology: Integrated Positive Practice. London: Sage Publications.

McCullough, M. E., Emmons, R. A., \& Tsang, J. (2002). The Grateful Disposition: A conceptual and Empirical Topography. Journal of Personality and Social Psychology, 82(1), 112-127. 
Moher, D., Schultz, K. F., \& Altman, D. G. (2001). The CONSORT statement: revised recommendations for improving the quality of reports of parallel-group randomized trials. Annals of internal medicine, 134(8), 657-62.

Neff, K. D., \& Germer, C. K. (2013). A Pilot Study and Randomized Controlled Trial of the Mindful Self-Compassion Program. Journal of clinical psychology, 69(1), 2844.

Niemiec, R. M., Rashid, T., \& Spinella, M. (2012). Strong mindfulness: Integrating mindfulness and character strengths. Journal of Mental Health Counseling, 34(3), 240-253.

Oishi, S., Diener, E., Choi, D., Kim-Prieto, C., \& Choi, I. (2007). The dynamics of daily events and well-being across cultures: When less is more. Journal of Personality and Social Psychology, 93(4), 685-698.

Parks, A. C., \& Biswas-Diener, R. (2013). Positive interventions: Past, present and future. In T. Kashdan \& Ciarrochi, J. (Eds.), Mindfulness, Acceptance and Positive Psychology: The Seven Foundations of Well-Being, (pp. 140-165). Oakland, CA: Context Press.

Pommier, E. A. (2011). The compassion scale. Dissertation Abstracts International Section A: Humanities and Social Sciences, 72, 1174.

Raes, F., Pommier, E. A., Neff, K. D., \& Van Gucht, D. (2011). Construction and factorial validation of a short form of the self-compassion scale. Clinical psychology \& psychotherapy, 18(3), 250-255.

Ritchie, T. D., \& Bryant, F. B. (2012). Positive state mindfulness: A multidimensional model of mindfulness in relation to positive experience. International Journal of Wellbeing, 2(3), 150-181.

Ryff, C. D., \& Keyes, C. L. M. (1995). The structure of psychological well-being revisited. Journal of personality and social psychology, 69(4), 719-727.

Ryff, C. D., \& Singer, B. (1998). The Contours of Positive Human Health. Psychological Inquiry, 9(1), 1-28.

Schwarzer, R., \& Jerusalem, M. (1995). Generalized self-efficacy scale. Measures in health psychology: A user's portfolio. Causal and control beliefs, 1, 35-37.

Seligman, M. E. P. \& Csikszentmihalyi, M. (2000). Positive psychology: An introduction. American Psychologist, 55, 5-14.

Shapiro, D. H. (1992a). A preliminary study of long term meditators: Goals, effects, religious orientation, cognitions. Journal of Transpersonal Psychology, 24(1), 23- 
39.

Shapiro, S. L., Carlson, L. E., Astin, J. A., \& Freedman, B. (2006). Mechanisms of mindfulness. Journal of clinical psychology, 62(3), 373-386.

Sin, N. L., \& Lyubomirsky, S. (2009). Enhancing well-being and alleviating depressive symptoms with positive psychology interventions: A practice-friendly metaanalysis. Journal of clinical psychology, 65(5), 467-487.

Steger, M. F., Frazier, P., Oishi, S., \& Kaler, M. (2006). The Meaning in Life Questionnaire: Assessing the presence of and search for meaning in life. Journal of Counseling Psychology, 53(1), 80-93.

Teasdale, J. D., Segal, Z. V., Williams, J. M. G., Ridgeway, V. A., Soulsby, J. M., \& Lau, M. A. (2000). Prevention of relapse/recurrence in major depression by mindfulness-based cognitive therapy. Journal of consulting and clinical psychology, 68(4), 615-623.

Walach, H., Buchheld, N., Buttenmüller, V., Kleinknecht, N., \& Schmidt, S. (2006). Measuring mindfulness - the Freiburg mindfulness inventory (FMI). Personality and Individual Differences, 40(8), 1543-1555.

Wallace, B. A., \& Shapiro, S. L. (2006). Mental balance and well-being: Building bridges between Buddhism and Western Psychology. American Psychologist, 61(7), 690-701. 